\title{
Commentary
}

\section{Value in Development of a TAPIR-Like Mouse Monoclonal Antibody to $\mathrm{A} \beta$}

\author{
Kumar Sambamurti*, Miguel A. Pappolla and K.S. Jagannatha Rao \\ Department of Neurosciences, Medical University of South Carolina, Charleston, SC, USA
}

\begin{abstract}
Alzheimer's disease (AD) is a progressive dementia with characteristic brain lesions known as senile plaques and neurofibrillary tangles (NFTs). Amyloid plaques contain the $38-42$ residue amyloid- $\beta$ protein $(\mathrm{A} \beta)$ and NFTs consist of the microtubule-associated protein, tau [18]. $\mathrm{A} \beta$ is synthesized as a larger precursor protein $-\mathrm{A} \beta \mathrm{PP}-$ and is generated by proteolytic processing by $\beta$ - and $\gamma$-secretases [15]. For a number of years, the field debated whether senile plaques or NFTs are causes of the disease or simply markers or tombstones that define AD. A major series of discoveries in the early 1990s started to place amyloid at the center of the disease pathology by finding mutations framing the $\mathrm{A} \beta$ sequence on $\mathrm{A} \beta \mathrm{PP}$ linked to rare familial AD (FAD). In addition, the field developed methods for analysis of small peptides and determined that the yield of either total $\mathrm{A} \beta$ or the longer $\mathrm{A} \beta 42$ fragment was increased in cells expressing FAD mutant $\mathrm{A} \beta \mathrm{PP}$. Subsequently, a larger number of FAD mutations linked to a subunit of $\gamma$-secretase termed presenilins (PS) 1 and 2 were identified. Most of these mutations also increased A $\beta 42$ levels. Since the longer A $\beta 42$ form readily aggregates to form amyloid deposits, the theory that amyloid plaques cause $\mathrm{AD}$ became well supported [7].

The finding that $\mathrm{A} \beta$ aggregates were neurotoxic in culture further supported the amyloid hypothesis. However, as the field matured, it became clear that there were a number of weaknesses in the one-dimensional
\end{abstract}

\footnotetext{
*Corresponding author. Tel.: +1 843792 4315; E-mail: sambak@ musc.edu.
}

hypothesis that $\mathrm{AD}$ is caused by toxicity of amyloid plaques, which are responsible for a spectrum of changes including the formation of NFTs. The vast majority of typical late onset $\mathrm{AD}$ lacked a clear series of risk factors for the accumulation of $\mathrm{A} \beta$. Furthermore, the epidemiology of AD lesions demonstrated that NFTs are more closely linked to dementia than senile plaques [2]. There is apparently a large genetic component to $\mathrm{AD}$ that has not yet been deciphered. Thus, it has become clear that AD is a more complex disease with a number of dimensions like cancer, and the need for more extensive funding to clearly understand and define the amyloid hypothesis as well as explore alternatives that are still in the early stages needs to be emphasized. A number of alternative hypotheses have been promulgated that either qualified the amyloid hypothesis or even proposed fresh alternative theories. These include: the hypothesis that apolipoprotein $\mathrm{E}$ (ApoE), the best defined risk factor for $\mathrm{AD}$, is the cause of the disease and other factors such as $\mathrm{A} \beta$ act on ApoE [4]; failure in energy metabolism in the brain similar to diabetes (Type III diabetes) [19]; metal ( $\mathrm{Cu}$, $\mathrm{Zn}$ ) homeostasis [1]; and the hypothesis that the disease arises from a more fundamental failure in metabolism of a large number of membrane proteins, including $\mathrm{A} \beta \mathrm{PP}$, that ultimately result in a multiple pathway failure due to accumulation of metabolic intermediate of multiple proteins [16].

The most popular among these is the theory that transient soluble $\mathrm{A} \beta$ aggregates (ADDLs), which are intermediates in amyloid plaque formation are neurotoxic and senile plaque lesions simply represent the spent 
shells in $\mathrm{AD}[6,11]$. This theory limits the forms of $\mathrm{A} \beta$ that are responsible for neurodegeneration and explains the failure to see clear correlation between dysfunction or loss of neurons and the senile plaque lesion characteristic of AD. Definition of the toxic intermediate form of $\mathrm{A} \beta$ then becomes crucial for the prevention and treatment of $\mathrm{AD}$. It is particularly important to develop methods to measure the levels of the active intermediate first in order to identify methods to prevent its formation. One approach was to purify the toxic $\mathrm{A} \beta$ intermediate and define its role by directly delivering to the brain and block it with specific antibodies. The efforts by Karen Ashe in identifying a key toxic dodecamer intermediate, $\mathrm{A} \beta * 56$, deserves special mention in this regard $[3,12]$.

The most extensive and successful anti-amyloid therapy attempted to date is the vaccination trial by Elan Corporation $[13,20]$. Unfortunately this trial had to be stopped due to treatment-induced encephalitis [17]. An important development associated with the trial was the development of an assay termed as the tissue amyloid plaque immunoreactivity (TAPIR) assay [8]. In this assay, the immune response in vaccinated patients was evaluated by using sections from either AD brain or transgenic mouse brain. The assay was used to demonstrate that the vaccination resulted in a strong immune reaction against the aggregated form of $\mathrm{A} \beta 42$ but not against $\mathrm{A} \beta \mathrm{PP}$ or its $\mathrm{C}$-terminal fragments. A follow up study showed that TAPIR reactivity correlated with improvement in cognition in the small subset of vaccinated subjects. However, although TAPIR response correlated well with A $\beta 42$ ELISA response, the latter did not correlate well with improved cognition $[9,10]$. These studies clearly suggested that there may be specific forms of $\mathrm{A} \beta$ that lead to cognitive decline but most $\mathrm{A} \beta$ is normally well tolerated.

These findings emphasize that the role of $\mathrm{A} \beta$ in $\mathrm{AD}$ pathogenesis is complex and that a simple failure of an $\mathrm{A} \beta$-lowering clinical trial does not necessarily rule out the amyloid hypothesis. Instead, more research is required in understanding the mechanisms that link changes in $\mathrm{A} \beta \mathrm{PP}$ metabolism with $\mathrm{AD}$ in addition to examining alternative hypotheses. The paper by Wang et al. [21] is among the first to take advantage of this interesting finding and make an antibody, 3.4A10, that shows the same TAPIR-like immunoreactivity. This will help considerably in assays to follow up on the numerous $\mathrm{A} \beta$-lowering clinical trials that should be completed fairly soon. In addition, this antibody may prove to be particularly useful for immunotherapy as it targets the specific subset of epitopes associated with improved retention of cognition over time in AD patients. The disruption of amyloid plaque in general may lead to an increase in toxic soluble $\mathrm{A} \beta$ oligomers and may therefore be undesirable. In addition, the inert amyloid plaque deposits are extensive and may provide structural support to the collapsing tissue around it and thus its removal may lead to distortion of neuronal connections. Indeed, the Elan clinical trial was not only fraught with difficulties associated with inflammation, but also with data showing shrinkage of brain upon plaque removal and an increased worsening of cognitive performance in patients with successful plaque removal $[5,14]$. It is particularly heartening to note that this study finds that treatment with the TAPIR-like antibody, 3.4A10, results in a reduction of plaques as well as $\mathrm{A} \beta^{*} 56$. In addition, there is evidence of reduced adverse effects such as microhemorrhages in the brain upon treatment with the 3.4A10 when compared to vaccination. In addition the antibody treatment did not show signs of inflammatory changes, at least in the TG2576 mouse model. Clearly these are early preclinical studies that need to be developed more thoroughly for use in diagnosis as a biomarker, passive immune treatment or evaluation of therapeutic agents that lower $\mathrm{A} \beta$. Nevertheless it represents an important step forward to ultimately treat this intractable disease.

\section{References}

[1] P.A. Adlard and A.I. Bush, Metals and Alzheimer's disease, $J$ Alzheimers Dis 10 (2006), 145-163.

[2] D.A. Bennett, J.A. Schneider, R.S. Wilson, J.L. Bienias and S.E. Arnold, Neurofibrillary tangles mediate the association of amyloid load with clinical Alzheimer disease and level of cognitive function, Arch Neurol 61 (2004), 378-384.

[3] I.H. Cheng, K. Scearce-Levie, J. Legleiter, J.J. Palop, H. Gerstein, N. Bien-Ly, J. Puolivali, S. Lesne, K.H. Ashe, P.J. Muchowski and L. Mucke, Accelerating amyloid-beta fibrillization reduces oligomer levels and functional deficits in Alzheimer disease mouse models, J Biol Chem 282 (2007), 23818-23828.

[4] K.A. Crutcher, Apolipoprotein E is a prime suspect, not just an accomplice, in Alzheimer's disease, J Mol Neurosci 23 (2004), 181-188.

[5] N.C. Fox, R.S. Black, S. Gilman, M.N. Rossor, S.G. Griffith, L. Jenkins and M. Koller, Effects of Abeta immunization (AN1792) on MRI measures of cerebral volume in Alzheimer disease, Neurology 64 (2005), 1563-1572.

[6] J. Hardy and D.J. Selkoe, The amyloid hypothesis of Alzheimer's disease: progress and problems on the road to therapeutics, Science 297 (2002), 353-356.

[7] J. Hardy, Has the amyloid cascade hypothesis for Alzheimer's disease been proved? Curr Alzheimer Res 3 (2006), 71-73.

[8] C. Hock, U. Konietzko, A. Papassotiropoulos, A. Wollmer, J. Streffer, R.C. von Rotz, G. Davey, E. Moritz and R.M. Nitsch, Generation of antibodies specific for beta-amyloid by 
vaccination of patients with Alzheimer disease, Nat Med 8 (2002), 1270-1275.

[9] C. Hock, U. Konietzko, J.R. Streffer, J. Tracy, A. Signorell, B. Muller-Tillmanns, U. Lemke, K. Henke, E. Moritz, E. Garcia, M.A. Wollmer, D. Umbricht, D.J. de Quervain, M. Hofmann, A. Maddalena, A. Papassotiropoulos and R.M. Nitsch, Antibodies against beta-amyloid slow cognitive decline in Alzheimer's disease, Neuron 38 (2003), 547-554.

[10] C. Hock and R.M. Nitsch, Clinical observations with AN-1792 using TAPIR analyses, Neurodegener Dis 2 (2005), 273-276.

[11] W.L. Klein, Abeta toxicity in Alzheimer's disease: globular oligomers (ADDLs) as new vaccine and drug targets, $\mathrm{Neu}$ rochem Int 41 (2002), 345-352.

[12] S. Lesne, M.T. Koh, L. Kotilinek, R. Kayed, C.G. Glabe, A. Yang, M. Gallagher and K.H. Ashe, A specific amyloid-beta protein assembly in the brain impairs memory, Nature $\mathbf{4 4 0}$ (2006), 352-357.

[13] D. Martindale, Peeling plaque. Researchers remain optimistic about a vaccine against Alzheimer's, Sci Am 286 (2002), 18, 20.

[14] J.A. Nicoll, E. Barton, D. Boche, J.W. Neal, I. Ferrer, P. Thompson, C. Vlachouli, D. Wilkinson, A. Bayer, D. Games, P. Seubert, D. Schenk and C. Holmes, Abeta species removal after abeta42 immunization, J Neuropathol Exp Neurol 65 (2006), 1040-1048.
[15] K. Sambamurti, N.H. Greig and D.K. Lahiri, Advances in the cellular and molecular biology of the beta-amyloid protein in Alzheimer's disease, Neuromolecular Med 1 (2002), 1-31.

[16] K. Sambamurti, A. Suram, C. Venugopal, A. Prakasam, Y. Zhou, D.K. Lahiri and N.H. Greig, A partial failure of membrane protein turnover may cause Alzheimer's disease: a new hypothesis, Curr Alzheimer Res 3 (2006), 81-90.

[17] D. Schenk, Amyloid-beta immunotherapy for Alzheimer's disease: the end of the beginning, Nat Rev Neurosci 3 (2002), 824-828.

[18] D.J. Selkoe, Alzheimer's disease: genes, proteins, and therapy, Physiol Rev 81 (2001), 741-766.

[19] E. Steen, B.M. Terry, E.J. Rivera, J.L. Cannon, T.R. Neely, R. Tavares, X.J. Xu, J.R. Wands and S.M. de la Monte, Impaired insulin and insulin-like growth factor expression and signaling mechanisms in Alzheimer's disease - is this type 3 diabetes? J Alzheimers Dis 7 (2005), 63-80.

[20] U. Thatte, AN-1792 (Elan), Curr Opin Investig Drugs 2 (2001), 663-667.

[21] J. Wang, H. Hara, T. Makifuchi and T. Tabira, Development and characterization of a TAPIR-like mouse monoclonal antibody to Amyloid- $\beta$, J Alzheimers Dis 14(2) (2008) 161-173, 